\title{
Time-averaged Turbulent Flow Characteristics over a Highly Spatially Heterogeneous Gravel-Bed
}

\author{
Sankar SARKAR \\ Physics and Applied Mathematics Unit, Indian Statistical Institute, \\ Kolkata, West Bengal, India; e-mail: sankar79_v@isical.ac.in
}

\begin{abstract}
The present study focuses on the time-averaged turbulence characteristics over a highly spatially-heterogeneous gravel-bed. The timeaveraged streamwise velocity, Reynolds shear and normal stresses, turbulent kinetic energy, higher-order moments of velocity fluctuations, length scales, and the turbulent bursting were measured over a gravel-bed with an array of larger gravels. It was observed that the turbulence characteristics do not vary significantly above the crest level of the array as compared to those below the array. The nondimensional streamwise velocity decreases considerably with a decrease in depth below the array. Below the array, the Reynolds shear stress (RSS) deviates from the gravity-law of RSS distributions. Turbulence intensities reduce below the crest level of the gravel-bed. The third-order moments of velocity fluctuations increase below the crest level of the gravel-bed and give a clear indication of sweeps as the predominating event which were further verified with the quadrant analysis plots. The turbulent length scales values change significantly below the crest level of the gravel-bed.
\end{abstract}

Key words: hydraulics, open channel flow, stream beds, time-averaged flow characteristics, turbulent flow. 


\section{INTRODUCTION}

Turbulent flow over a gravel-bed is a matter of immense interest to the researchers because of its practical and theoretical importance in the field of eco-environmental hydrodynamics, geology, physics and applied mathematics, etc. A river-bed formed by gravel clusters with different shapes, sizes and arrangements creates a highly rough bed those are mostly found in the upper reaches of a mountain river. Characterizing the turbulence parameters for these river-beds are troublesome due to the spatial heterogeneity created by the roughness. For instance, in and around rock-ramp fishways found in a mountain river, the gravel-bed becomes highly spatially heterogeneous due to the presence of larger gravels (boulders). These boulders act as a protrusion or bluff-body over the rough-bed and they play an important role for the fish-habitat (Van Zyll de Jong et al. 1997). Best and Brayshaw (1985), and Acarlar and Smith (1987) observed that the macroturbulent flow structures are generated atop the relatively larger gravels of a gravel-bed and shed the mesoscale structures. These macroturbulent flow structures scale with the roughness element height near the point of shedding, as was observed by Duncan (1970). Best (1996) observed that these intermittent shedding structures are caused by the separation of shear zone at the downstream of the protrusion. Kirkbride (1993) also observed that the turbulent flow characteristics in gravel-bed streams are influenced by the heterogeneous bed topography composed of protruding discrete particles. Study of these types of rough beds is therefore important to understand the interaction between the flow and roughness. However, to study the general turbulent behaviour over this type of beds, spatial or double-averaging methodology is more applicable, where the time-averaged flow parameters are also averaged over a layer parallel to the mean bed level at an elevation (Nikora et al. 2001, 2004, 2007a, b; Aberle et al. 2008, Mignot et al. 2009a, b; Sarkar and Dey 2010, Dey and Das 2012). However, in the present case, the time-averaged values were used to study the local flow characteristics created by the spatial heterogeneity in the rough-bed.

In the experimental studies of turbulent flow over a gravel-bed, Nikora et al. (2001) chose spherical segment-type bed; whereas Mignot et al. (2009a, b), Sarkar and Dey (2010), and Dey and Das (2012) used beds of angular crushed stones, loosely compacted round-shaped gravels and relatively closely packed round shaped gravels, respectively. However, in those studies, uniformly graded roughness elements were used to create the bed roughness. On the other hand, to handle the problem more practically, Brayshaw (1984), Buffin-Bélanger and Roy (1998), Buffin-Bélanger et al. (2006), Lacey and Roy (2007), and Lacey et al. (2007) worked with nonuniform gravel beds those were created by the pebble clusters. Lacey and Roy (2007) 
studied a detailed 3-D turbulent flow characteristic around a pebble cluster. They importantly observed the interactions between macroscale and mesoscale turbulent coherent flow structures in a gravel bed river. Using the contour plots, they showed that pebble clusters influence the flow field quite locally and their effect is limited to the near-bed region only. Using the double-averaging methodology, Tamagni et al. (2014) showed that the flow layers change from the existing double-averaged layers in presence of unstructured block ramps. They suggested a new subdivision of the interfacial sublayer for this type of gravel-bed. Previous studies of Dey et al. (2011) and Papanicolaou et al. (2012) showed that almost all the turbulence parameters change their behaviour in near- and far-wake regions in the presence of protrusion over a rough bed. Dey et al. (2011) observed that the profiles of the defects in the streamwise velocity, RSS and turbulence intensities exhibit some degree of similarities when they are scaled by their respective peak defect values. The similarity solution for the profiles of the velocity defect in steady-state wall-wake flows was also established theoretically by them. However, for the present study the bed profile is different from that of Dey et al. (2011). In Dey et al. (2011), the ratio of the diameter of the spherical protruded body and the mean diameter of gravel were $D / d_{50}=7.55,11.32$, and 15.09; whereas in the present study, the ratio of the mean diameter of the protruding larger gravel and the diameter of gravel that used in the bed is $D / d_{50}=1.25$ only.

\section{EXPERIMENTAL SETUP AND INSTRUMENTATION}

An experimental setup was prepared in the fluvial mechanics laboratory of Indian Statistical Institute, Kolkata, India. The experiment was performed in a rectangular recirculatory flume that was $20 \mathrm{~m}$ long (total), $0.5 \mathrm{~m}$ wide, and $0.5 \mathrm{~m}$ deep. The transparent side-walls of the flume for a length of $8 \mathrm{~m}$ facilitated observation of the flow in the measuring zone. Experiment was conducted under a uniform flow condition with a streamwise bed slope $(S)$ of $0.35 \%$. The bed was made with uniformly sorted natural gravels of a median size $d_{50}=40 \mathrm{~mm}$ with uniformity coefficient, $\sigma_{g}=1.23$, where $\sigma_{g}=\left(d_{84} / d_{16}\right)^{0.5}$. The gravels were laid in three to four layers over the floor of the channel. Above these layers, a gravel array was made with larger artificial gravels of median size of $D_{50}=50 \mathrm{~mm}$ and $\sigma_{g}=1.1$. The centre-tocentre distance between the protruding gravels was approximately $5 D_{50}$. The bed slope and bed surface fluctuations were checked at every $5 \mathrm{~mm}$ along the centerline of the flume using a Vernier point gauge with a precision of $\pm 0.1 \mathrm{~mm}$. The velocity measurement was started at the distance of $7 \mathrm{~m}$ from the inlet of the flume. There was no movement of the gravels during the experiment. A schematics diagram and a photograph of the gravel-bed ar- 


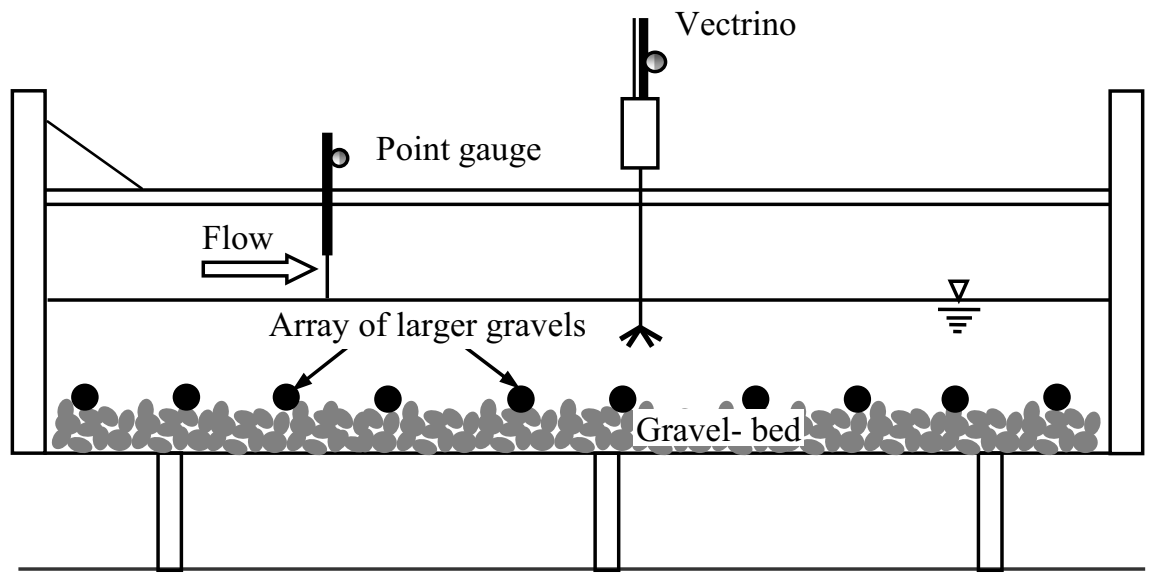

Fig. 1a. Schematic of the experimental set-up.

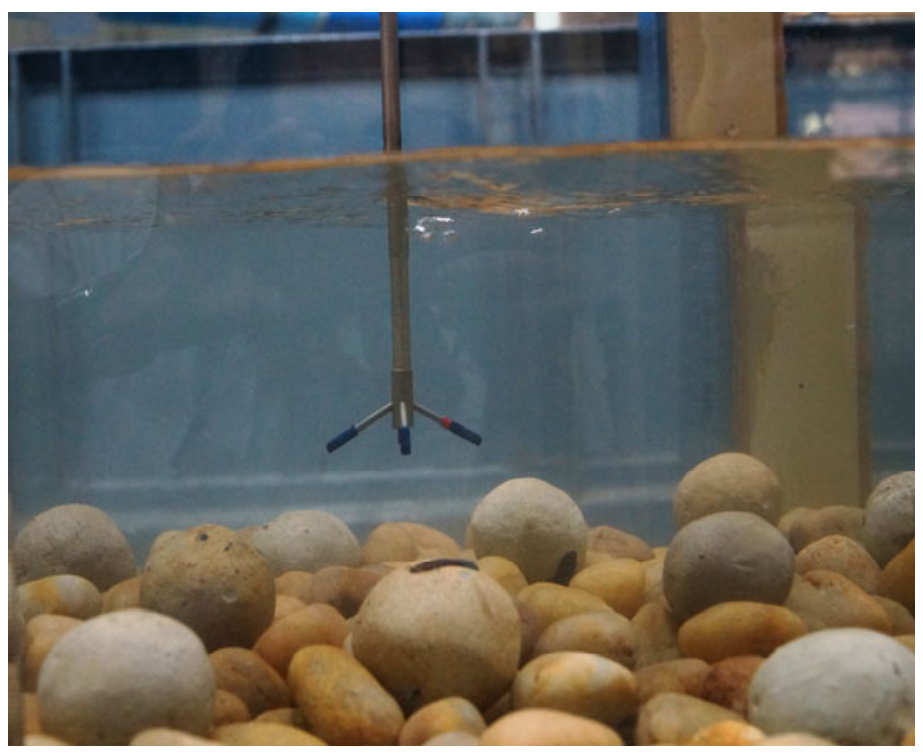

Fig. 1b. Photograph of the gravel-bed arrangement.

Table 1

Experimental parameters

\begin{tabular}{|c|c|c|c|c|c|c|c|}
\hline $\begin{array}{c}U \\
{[\mathrm{~m} / \mathrm{s}]}\end{array}$ & $\begin{array}{c}H \\
{[\mathrm{~m}]}\end{array}$ & $\begin{array}{c}S \\
{[\%]}\end{array}$ & $\begin{array}{c}d_{50} \\
{[\mathrm{~mm}]}\end{array}$ & $\begin{array}{c}D_{50} \\
{[\mathrm{~mm}]}\end{array}$ & $\begin{array}{c}\sigma_{g} \text { of } \\
d_{50}\end{array}$ & $\begin{array}{c}\sigma_{g} \text { of } \\
D_{50}\end{array}$ & $\begin{array}{c}u * \\
{\left[\mathrm{~ms}^{-1}\right]}\end{array}$ \\
\hline 0.63 & 0.159 & 0.35 & 40 & 50 & 1.23 & 1.1 & 0.076 \\
\hline
\end{tabular}


rangement are shown in Fig. 1a and 1b, respectively. The details of the experimental parameters are depicted in Table 1.

After preparing the bed, water was applied by a pump to achieve the required flow depth. A Nortek ${ }^{\circledR}$ made Vectrino was used to measure the instantaneous three-dimensional velocity components. The Vectrino is a type of 4-beam acoustic Doppler velocimeter (ADV). It was operated with an acoustic frequency of $10 \mathrm{MHz}$ and a sampling rate of $100 \mathrm{~Hz}$. The four acoustic beams meet at a distance of $50 \mathrm{~mm}$ below the probe head. The instrument is therefore capable of capturing the velocity data from $50 \mathrm{~mm}$ down, where the acoustic beams form a vertical cylindrical sampling volume of $6 \mathrm{~mm}$ diameter and 1-4 $\mathrm{mm}$ user adjustable height. As the measuring location was $50 \mathrm{~mm}$ below the probe, the instrument could not affect the measured data but at the same time the instrument was not capable in capturing data from top $50 \mathrm{~mm}$ of the flow depth. A sampling duration of $300 \mathrm{~s}$ was adequate to achieve the time-independent averaged velocity components. Up to the nondimensional vertical distance $z^{+}=0.15\left(z^{+}=z / h\right.$, where $z=$ the vertical distance measured with respect to crest level of the gravelbed, and $h=$ total flow depth measure with respect to the $z$ ), the lowest sampling height of the Vectrino measurements was $1 \mathrm{~mm}$. The lowest measuring point was $17 \mathrm{~mm}$ below the crest level of the gravel-bed. For the flow zone above $z^{+}=0.15$, the sampling height was $4 \mathrm{~mm}$. In general, the Vectrino signal correlation values greater than $70 \%$ were maintained as the minimum. However, nearest the bed, the range of the Vectrino signal correlation was $70 \pm 5 \%$ due to highly fluctuated values of the velocity components. Throughout the experiment, the minimum SNR (signal-to-noise ratio) was maintained as 17 . The removal of spikes from the raw data was performed

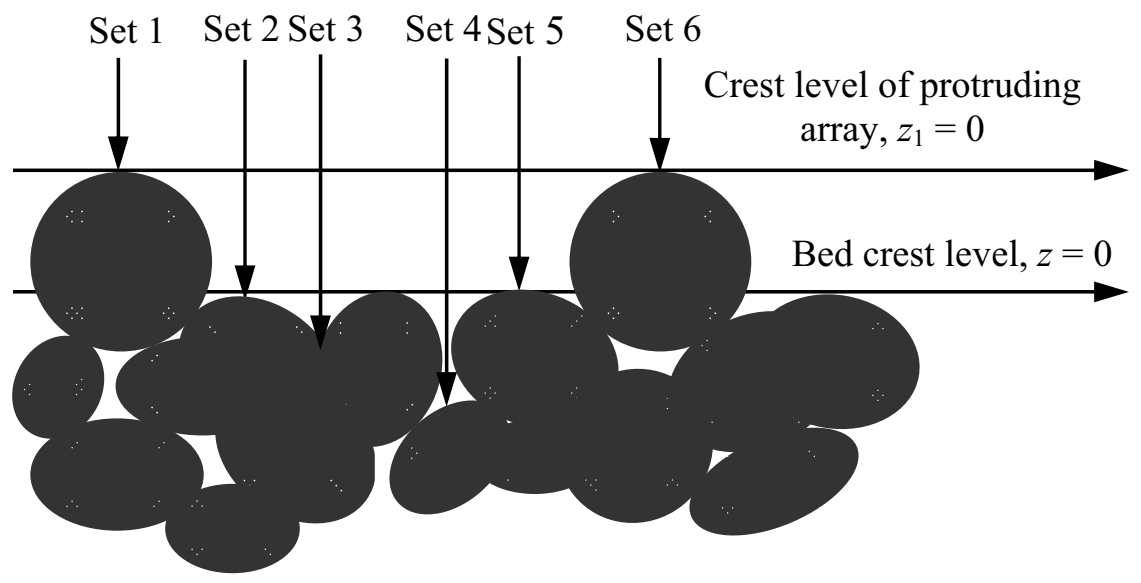

Fig. 2. Schematic of the bed profile and data capturing locations. 
by the digital filtration and the acceleration threshold method (Goring and Nikora 2002). The despiking was done until the velocity power spectra fit with Kolmogorov -5/3-law in the inertial subrange of frequency.

The streamwise ( $x$-direction), lateral ( $y$-direction), and vertical (z-direction) velocity components were indicated by $u, v$, and $w$, respectively. The crest level of the gravel-bed was considered as the reference level of the vertical distance, where $z=0$ (or $z^{+}=0$ ), and the crest level of the protruding array was considered as $z_{1}=0$ (or $z^{+}=0.2$ ) which was approximately $32 \mathrm{~mm}$ above the reference bed-level. Six different locations were chosen throughout the centerline of the flume for the measurement of the vertical profiles. The distances between two measuring locations were approximately the diameter of the protruding larger gravel, $D$. The locations were chosen in such a way that the first and sixth locations were onto the crest level of the larger protruding gravel, second and fifth were onto the crest level of the gravel-bed, third was at the junction between two gravels of the bed, and fourth one was at the aperture between two gravels of the bed. The data sets corresponding to the measuring locations were numbered as Set 1, Set 2, Set 3 , Set 4 , Set 5 , and Set 6 , as shown in Fig. 2. The shear velocity $u *$ (as appeared in Table 1) was determined from the measured RSS distributions of data Set 5 that was used for the nondimensionalising. The measured RSS profile was extrapolated linearly onto the crest level of the gravel-bed $z=0$. The shear velocity was therefore obtained as: $u_{*}=\left.\left(-\overline{u^{\prime} w^{\prime}}\right)^{0.5}\right|_{z=0}$. The value of $u_{*}$ from the bed slope, $(g h S)^{0.5}=0.074 \mathrm{~ms}^{-1}$, was very close to the value obtained from the RSS distribution $u_{* \text { stress }}=0.076 \mathrm{~ms}^{-1}$. The reason behind choosing the data Set 5 for the estimation of shear velocity is that its location was the farthest from the downstream protruding gravel according to the present bed profile.

\section{VELOCITY POWER SPECTRA}

After capturing the 3-D velocity components by Vectrino, the spectral analysis was done to plot the velocity power spectra at different vertical and horizontal distances. The spectral analysis was done using the discrete fast Fourier transforms (FFT). It was observed that the spike removing algorithm (acceleration threshold) followed by the digital filtration (for high-pass filter) gives a satisfactory velocity spectrum after some trial and error. The threshold values for spike removing were taken in the ranges from 1 to 1.5. However, two sets of velocity power spectra are shown in Fig. $3 a$ and $b$ for before and after the spike removal, respectively, as an example. The velocity power spectra show that within the inertial subrange, all the velocity power spectra exhibit the similar correlation between the velocity components as $F_{u u}(f) \approx$ 

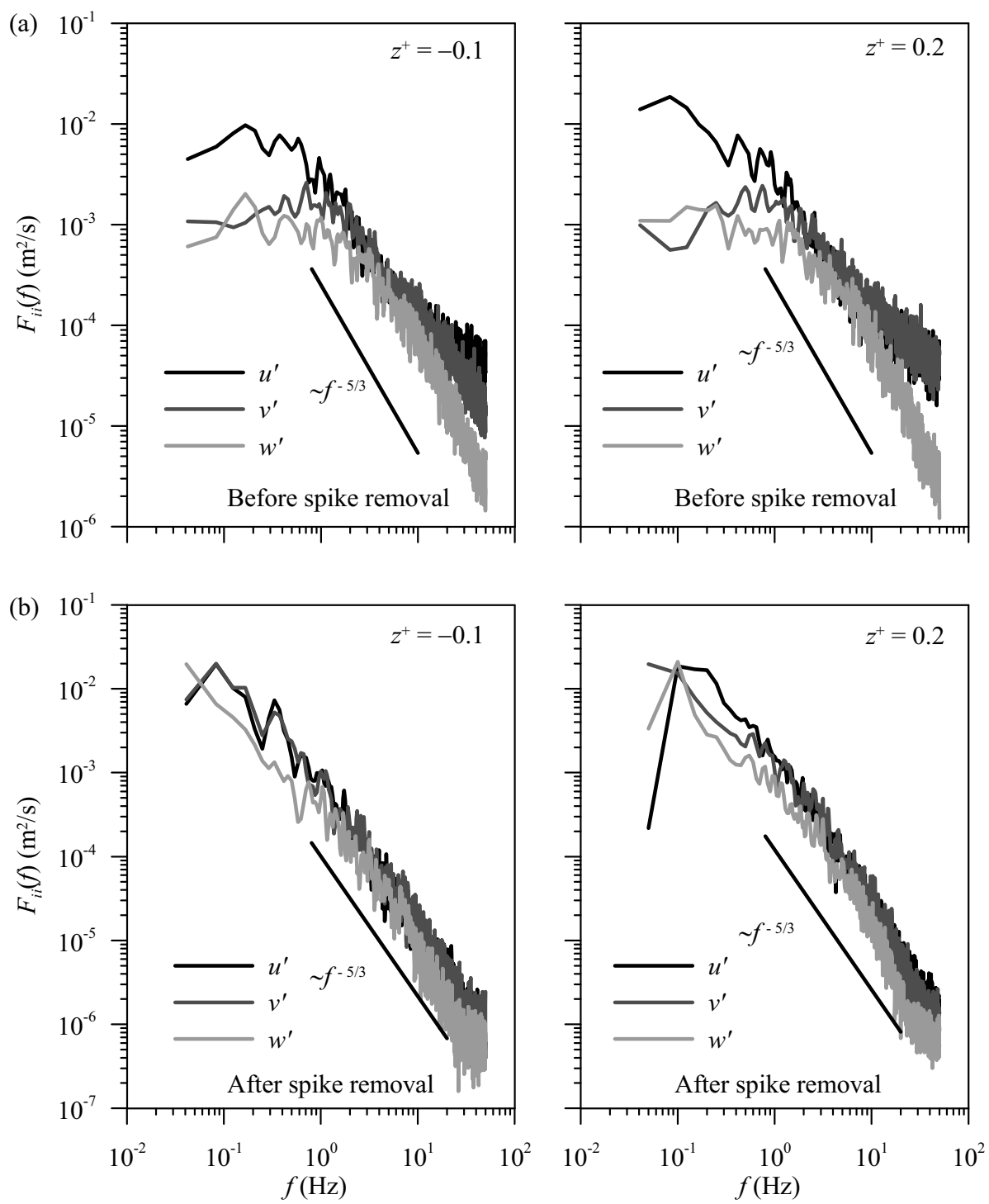

Fig. 3. Velocity power spectra $F_{i i}(f)$ at elevations $z^{+}=-0.2$ and $z^{+}=0.2$ (a) before spike removal, and (b) after spike removal.

$F_{v v}(f)>F_{w w}(f)$ and after removing the spike they follow the Kolmogorov $-5 / 3$ slope. It is pertinent to mention here that the accuracy of the estimation for turbulent kinetic energy (TKE) dissipation rate $\varepsilon$ depends on the accuracy of the velocity power spectrum, as the later is calculated from the velocity power spectrum. 


\section{TIME-AVERAGED STREAMWISE VELOCITY}

Figure 4 presents the flow field displaying the nondimensional timeaveraged velocity vector plots on the vertical plane of symmetry. The magnitude and the direction of the velocity vectors were $\left(\bar{u}^{2}+\bar{w}^{2}\right)$ and arctan $(\bar{w} / \bar{u})$, respectively. The vectors presented here correspond to the local nondimensional time-averaged velocity magnitudes relative to the depthaverage velocity $U$.

It is evident from Fig. 4 that underneath crest level of the gravel-bed, the flow is highly spatially heterogeneous. Particularly below $z^{+}=0.1$, the local time-averaged velocities show negative values (or very small values) on the lee-side of the gravels, due to the wake formation. However, up to the upper half of the protruding larger gravel $(z / D=0.1)$, no effect of the protrusion was observed in the direction of velocity; whereas at the lower half of the protruding gravel, time-averaged velocity becomes negative, indicating a wake effect due to protrusion. It is important to mention here that the protruding effect due to the gravel-array was not so prominent as compared to those observed in Dey et al. (2011). The reason behind this may be the differences in bed profiles and flow parameters. Dey et al. (2011) performed the experiment over a gravel bed with smaller diameter $\left(d_{50}=2.65 \mathrm{~mm}\right)$ and the diameters of the protrusions were $D=20,30$, and $40 \mathrm{~mm}$ (i.e., $D / d_{50} \approx$ $7.55,11.32$, and 15.09). On the other hand, in the present case, $D / d_{50}=1.25$. Also, the ratio of height of protrusion above the bed $\left(D_{1}\right)$ to the $d_{50}$ of the

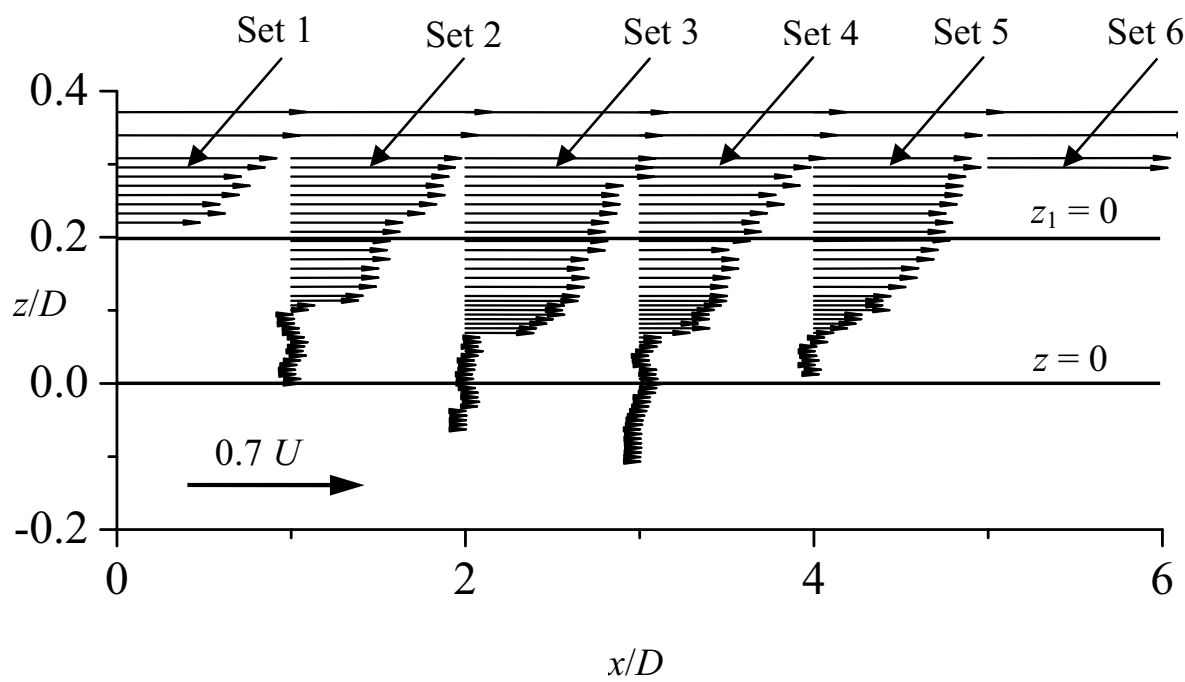

Fig. 4. Flow field represented by vectors of time-averaged velocity on the vertical plane of symmetry. 


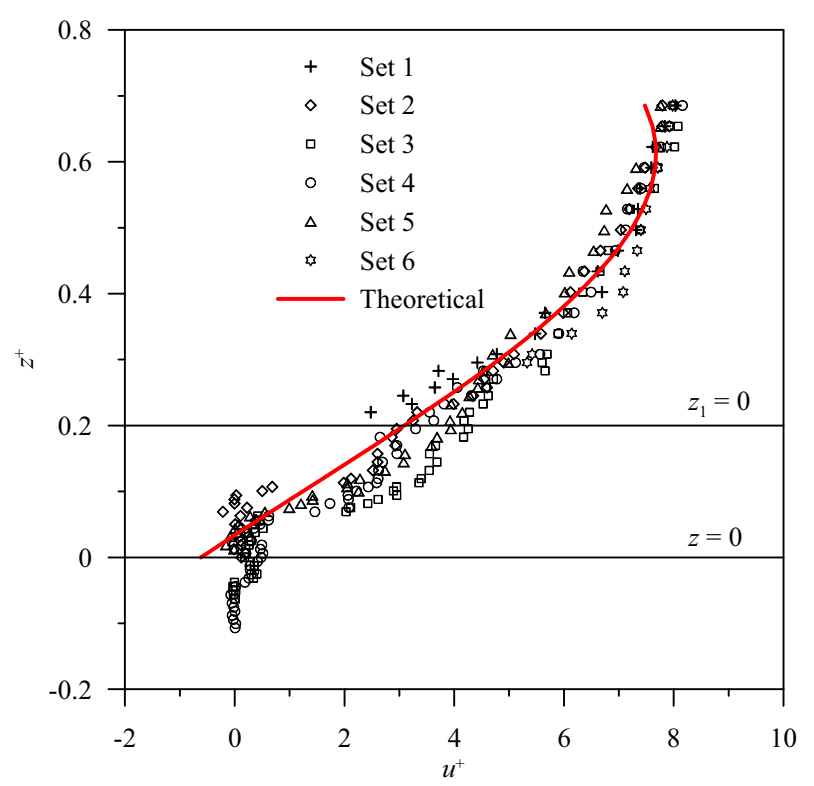

Fig. 5. Variations of nondimensional streamwise velocity $u^{+}$with nondimensional vertical distance $z^{+}$.

gravel were $D_{1} / d_{50}=6.79,9.06$, and 11.32 ; whereas in the present case, $D_{1} / d_{50}=0.8$. The depth-averaged velocity for Dey et al. (2011) was $U=0.408 \mathrm{~m} \mathrm{~s}^{-1}$; whereas in the present experiment $U=0.63 \mathrm{~m} \mathrm{~s}^{-1}$. The Froude numbers $F r\left(=U /(g h)^{1 / 2}\right)$ in Dey et al. (2011) was 0.34 and in the present case it is 0.5 . It is therefore concluded that the effect of protrusion reduces with a decrease in the values of $D / d_{50}$ and with an increase in the value of $U$. However, the experimental setup and aim of the present study is different from those of Dey et al. (2011).

Figure 5 shows the variations of nondimensional streamwise velocity $u^{+}$ $\left(=u / u_{*}\right)$ with nondimensional vertical distance $z^{+}$. It is clearly observed that the velocity plots for all the sets collapse on a single thin band above $z_{1}=0$. On the other hand, the band thickens below $z_{1}=0$. The velocity profiles above $z=0$ may be presented by a third-order polynomial $\left(z^{+}=0.0013 u^{+3}\right.$ $\left.-0.009 u^{+2}+0.068 u^{+}+0.0342\right)$; whereas below $z=0$, the $u^{+}$decreases significantly and almost invariant with respect to depth. However, the thirdorder polynomial is used here to show the trend of the velocity profile above $z=0$ which has no theoretical background.

\section{TIME-AVERAGED REYNOLDS SHEAR STRESS DISTRIBUTIONS}

The vertical variations of normalized Reynolds shear stress $u w^{+}\left(=-\overline{u^{\prime} w^{\prime}} /\right.$ $\left.\rho u *{ }^{2}\right)$ at different locations are shown in Fig. 6. It is observed from Fig. 6 that 

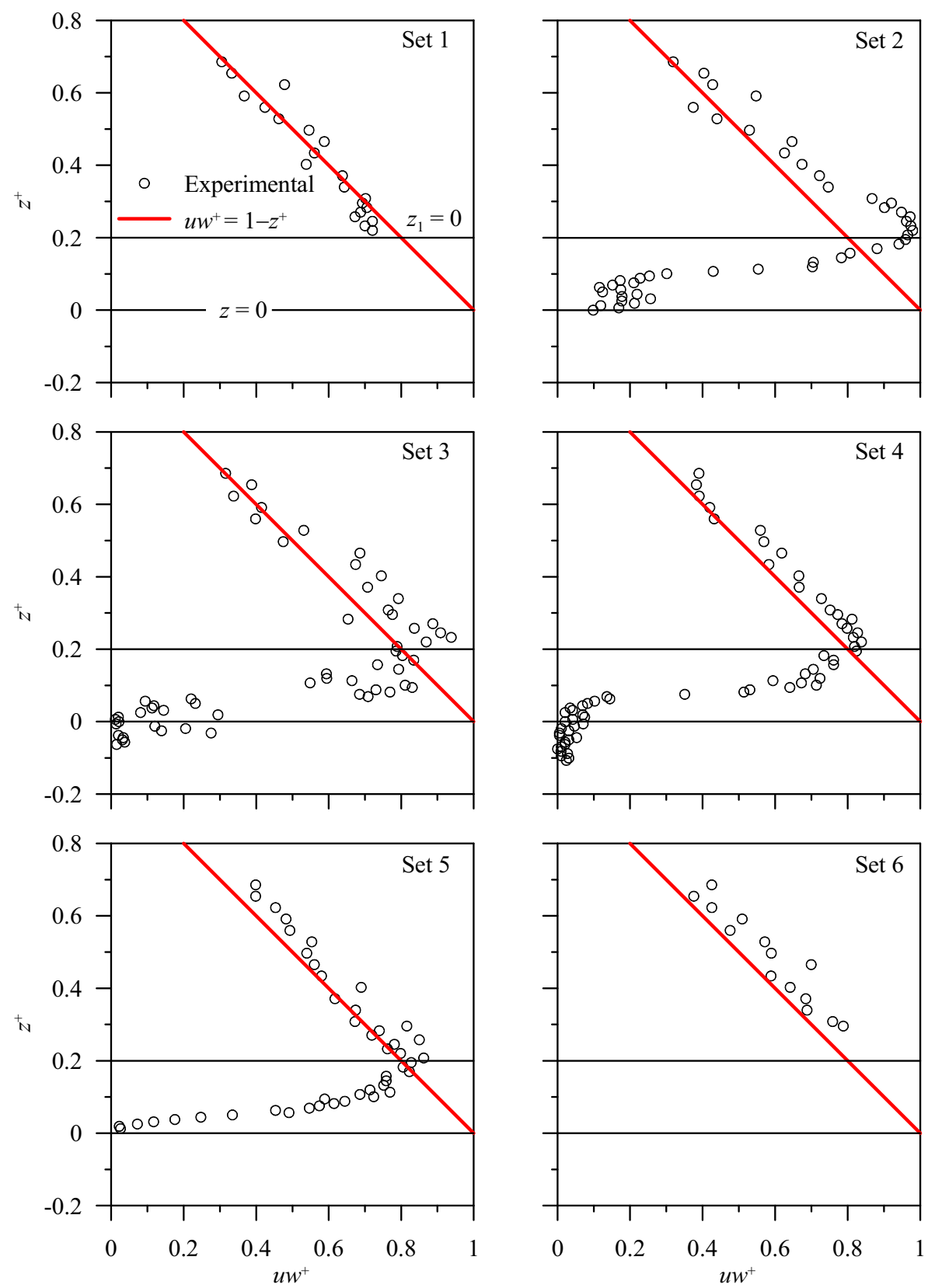

Fig. 6. Variations of nondimensional Reynolds shear stress $u w^{+}$with nondimensional vertical distance $z^{+}$at different locations. 
above $z_{1}=0$, the $u w^{+}$-plots are reasonably consistent with the traditional linear law of $u w^{+}$in uniform open channel flow, that is, $u w^{+}=1-z^{+}$. On the other hand, the variations of $u w^{+}$depart from the linear law below $z_{1}=0$. The $u w^{+}$attains its peak value at $z^{+}=0.2$, which decreases linearly with increase in $z^{+}$and decreases sharply with decrease in $z^{+}$. Below $z^{+}=0$, the values $u w^{+}$ become very small and invariant with $z^{+}$due to smaller values of the streamwise and vertical velocity components and corresponding fluctuations $\left(u^{\prime}\right.$ and $\left.w^{\prime}\right)$. Importantly, the values of $u w^{+}$are more at the immediate downstream of the protruding larger gravel within the vertical distance $z^{+}=0.15$ 0.3 , which is in confirmation with Dey et al. (2011) who observed that the value of $u w^{+}$increases at the immediate downstream of the protrusion. However, in the present study, the effect of protrusion is not clearly visible and the reason behind this is explained in the velocity description. It is therefore concluded that the Reynolds shear stress decreases at the near-bed due to the roughness and increases due to the protrusion.

\section{TIME-AVERAGED REYNOLDS NORMAL STRESSES DISTRIBUTIONS}

The streamwise, lateral and vertical Reynolds normal stresses (RNS) are $\sigma_{u u}=-\rho \overline{u^{\prime} u^{\prime}}, \sigma_{v v}=-\rho \overline{v^{\prime} v^{\prime}}$ and $\sigma_{w w}=-\rho \overline{w^{\prime} w^{\prime}}$, respectively. The nondimensional forms of $\sigma_{u u}, \sigma_{v v}$, and $\sigma_{w w}$ are: $\sigma_{u u}^{+}, \sigma_{v v}^{+}, \sigma_{w w}^{+}=\left(\sigma_{u u}, \sigma_{v v}, \sigma_{w w}\right) /\left(\rho u_{*}^{2}\right)$. The vertical distributions of $\sigma_{u u}^{+}, \sigma_{v v}^{+}$, and $\sigma_{w w}^{+}$at different locations are shown in Fig. 7. It is observed from Fig. 7 that all the $\sigma_{u u}^{+}, \sigma_{v v}^{+}$, and $\sigma_{w w}^{+}$attain their peak values slightly below the crest level of the protruding larger gravels and their values decrease above and below this level. The reason behind this is that the maximum turbulent mixing takes place at the roughness crest. Additionally, the larger protruding gravels over the bed are responsible to create an additional turbulent mixing. On the contrary, below the crest level of the protruding gravels, the damping in $\sigma_{u u}^{+}, \sigma_{v v}^{+}$, and $\sigma_{w w}^{+}$occurs which further decreases sharply below the crest level of the gravel-bed due to a decrease in temporal velocity fluctuations $\left(u^{\prime}\right.$ and $\left.w^{\prime}\right)$. Importantly, above $z_{1}=0$, the values of $\sigma_{u u}^{+}>\sigma_{v v}^{+}$irrespective of the locations of the measurement. Below $z=0$, the values of $\sigma_{u u}^{+}$and $\sigma_{v v}^{+}$become almost similar. On the other hand, $\sigma_{w w}^{+}$remains the smallest throughout the depth for all the locations. 

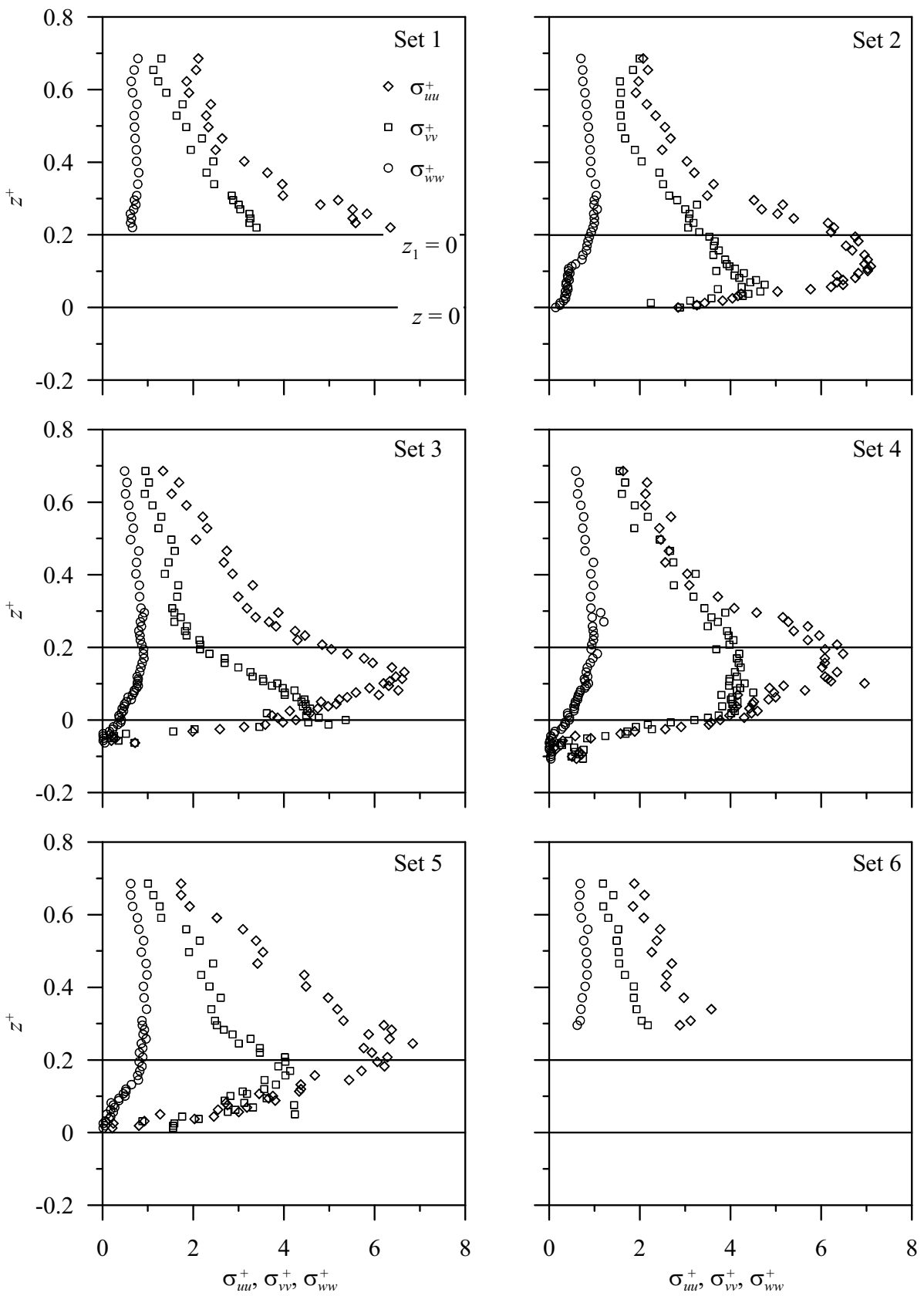

Fig. 7. Variations of $\sigma_{u u}^{+}, \sigma_{v v}^{+}$, and $\sigma_{w w}^{+}$, respectively with nondimensional vertical distance $z^{+}$at different locations. 

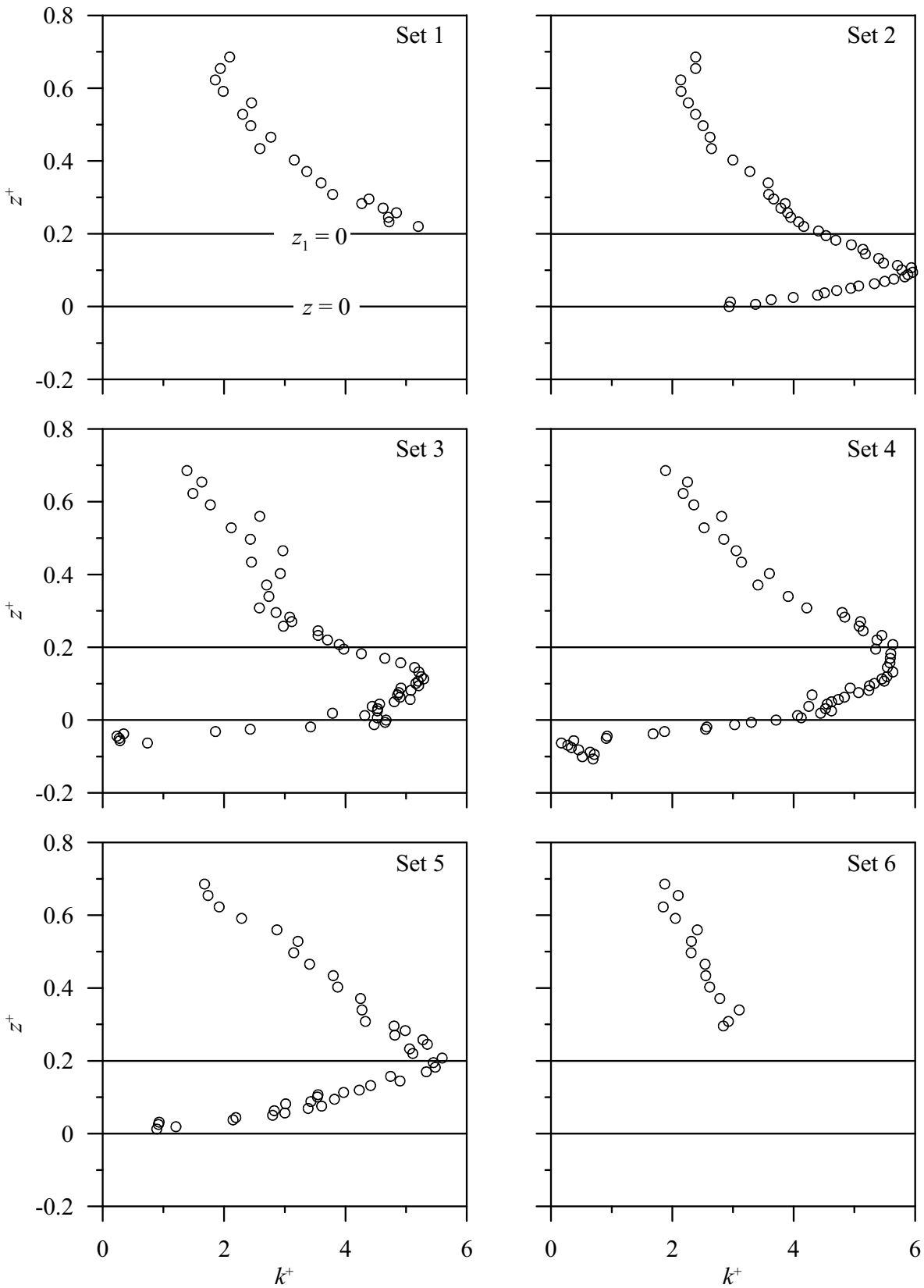

Fig. 8. Variations of nondimensional turbulent kinetic energy $\left(k^{+}\right)$with nondimensional vertical distance $z^{+}$at different sections. 


\section{TIME-AVERAGED TURBULENT KINETIC ENERGY DISTRIBUTIONS}

Turbulent Kinetic Energy (TKE), denoted by $k$, is the mean kinetic energy per unit mass of fluid and is calculated from the Reynolds normal stresses. Mathematically, the TKE is expressed as:

$$
k=0.5\left(\sigma_{u u}+\sigma_{v v}+\sigma_{w w}\right)
$$

The TKE is nondimensionalized as: $k^{+}=k / u_{*}^{2}$. The vertical distributions of nondimensional TKE at different locations are shown in Fig. 8. As was presumed from the $\sigma_{u u}^{+}-, \sigma_{v v}^{+}-$, and $\sigma_{w w}^{+}$-profiles, the value of $k^{+}$is maximum at the crest level of the protruding gravels. Above this level, the value of $k^{+}$decreases with increase in the vertical distance and below this, $k^{+}$decreases with decrease in the vertical distance. This is due to the fact that the maximum values of rms of the velocity fluctuations in terms of the Reynolds normal stress occur at the crest of the gravel-bed that is in confirmation with Dey and Das (2012).

\section{TIME-AVERAGED HIGHER-ORDER MOMENTS OF VELOCITY FLUCTUATIONS}

The third- and fourth-order moments of velocity fluctuations were calculated for different locations as shown in Figs. 9 and 10, respectively. Third-order moments of velocity fluctuations provide essential stochastic information on the temporal features of the velocity fluctuations in the form of flux of the turbulent stresses (Gad-el-Hak and Bandyopadhyay 1994). Another importance of the third-order moments is that they give a clear indication of the occurrence of bursting events in a fluid flow based on the quadrant analysis ( $\mathrm{Lu}$ and Willmarth 1973). According to Raupach (1981), the third-order moments of velocity fluctuations may be expressed as: $M_{j k}=\overline{\tilde{u}^{j} \tilde{w}^{k}}$ with $j+k=3$, where $\tilde{u}$ is $u^{\prime} /\left(\overline{u^{\prime} u^{\prime}}\right)^{0.5}$ and $\tilde{w}$ is $w^{\prime} /\left(\overline{w^{\prime} w^{\prime}}\right)^{0.5}$. Based on the values of $j$ and $k$ (0 to 3), the $M_{j k}$ may be classified as $M_{30}$ (i.e., skewness of $\left.u^{\prime}\right), M_{03}$ (i.e., skewness of $\left.w^{\prime}\right), M_{21}$ (i.e., diffusion of streamwise RNS in the vertical direction), and $M_{12}$ (i.e., diffusion of vertical RNS in the streamwise direction).

It is observed from Fig. 9 that the general trends of the $M_{j k}$-profiles are same above the vertical distance $z_{1}=0$ irrespective of the location of the measurements. On the other hand, below the vertical distance $z=0$, their values increase with a decrease in depth. Above $z^{+=} 0.1, M_{30}$ and $M_{21}$ are positive that indicate the positive values of $u^{\prime}$, and $M_{03}$ and $M_{12}$ are negative that indicate negative values of $w^{\prime}$. These positive values of $u^{\prime}$ and negative values of $w^{\prime}$ jointly give rise to the ejection events that are predominating 

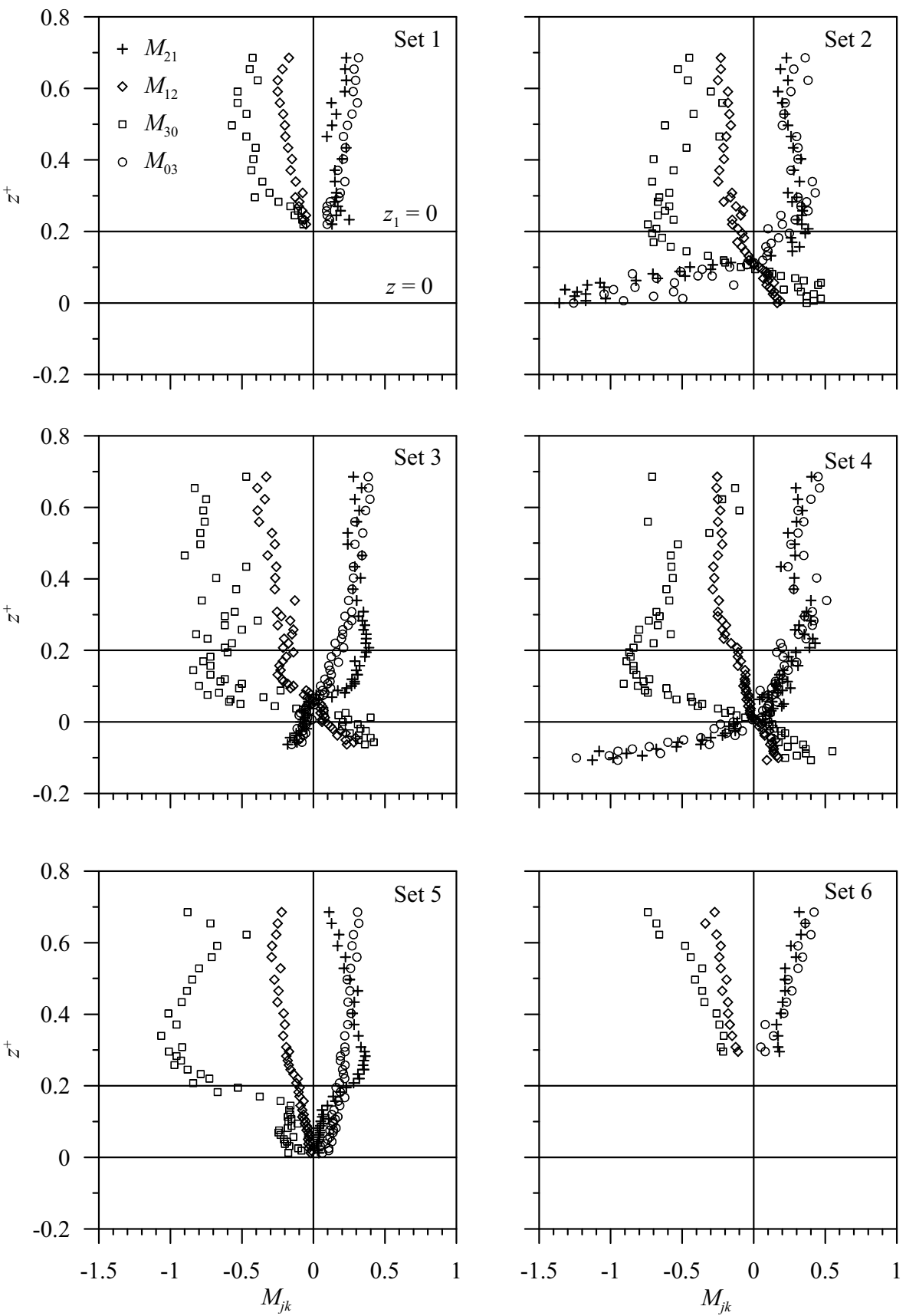

Fig. 9. Variations of nondimensional third-order moments $M_{j k}$ with $z^{+}$. 

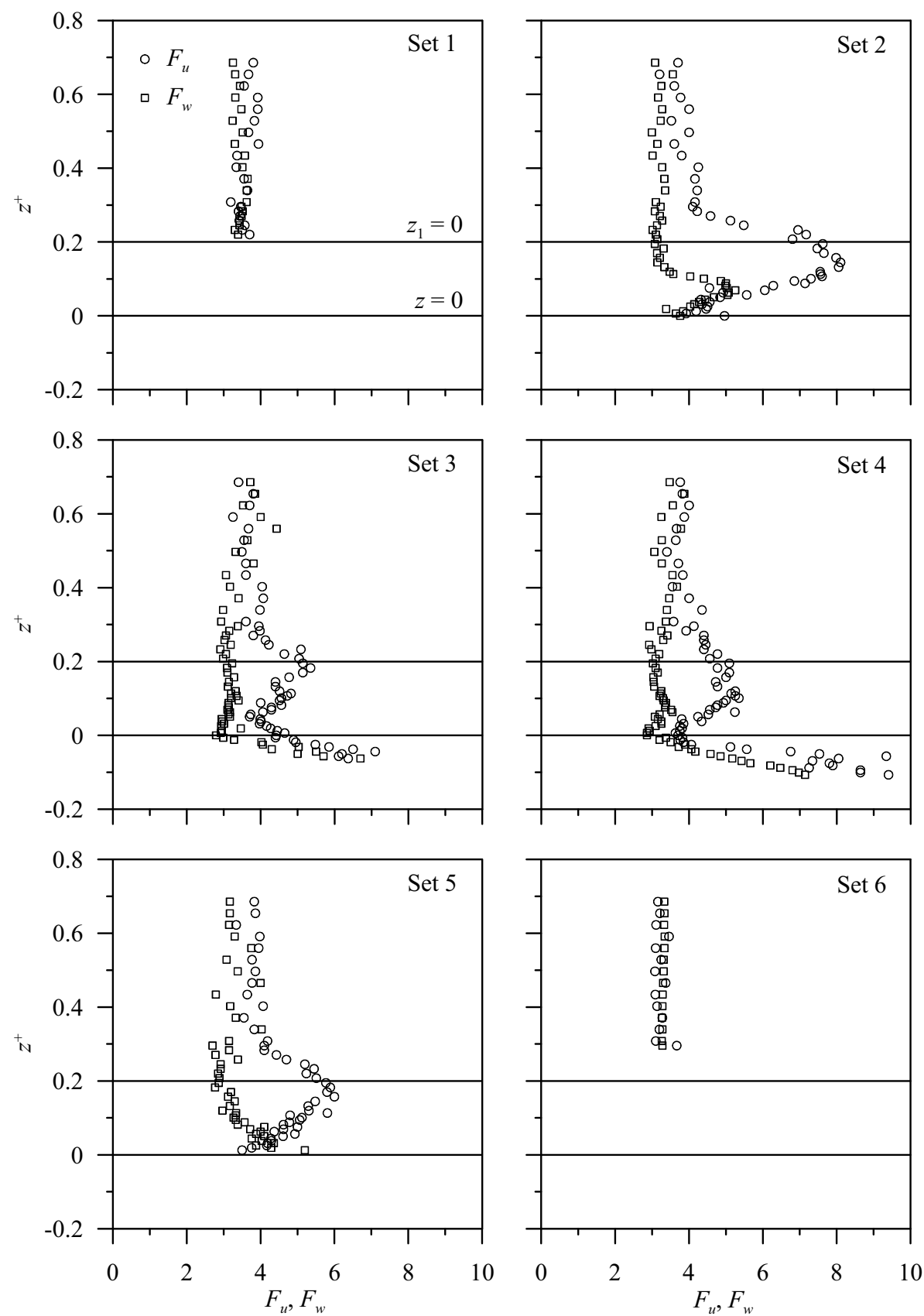

Fig. 10. Variations of nondimensional fourth-order moments, $F_{u}$ and $F_{w}$ with $z^{+}$. 
above $z^{+}=0.1$ irrespective of the position of the measurement. On the other hand, at the immediate downstream of the protruding gravel, at $z^{+} \leq 0.1$, all the third-order moments change their signs, indicating a changeover of the predominating bursting events from ejections $\left(u^{\prime}<0, w^{\prime}>0\right)$ to sweeps $\left(u^{\prime}>\right.$ $\left.0, w^{\prime}<0\right)$. For the data Set 3, changeover of the bursting events take place close to the vertical distance $z^{+}=0$. For the data Sets 3 and 4, the changeover of the bursting events take place exactly at $z^{+}=0$. For the data Set 6 , the third-order moments show the similar characteristics as that of Set 1. It is therefore concluded that the bursting events get affected by the presence of protrusion, as was observed by Dey et al. (2011) at the immediate downstream. The effect of the protrusion becomes less with increase in the streamwise distance, and therefore, the level of the changeover of bursting events changes. However, at $z^{+} \leq 0$, the changeover of the bursting events take place due to the local roughness in the bed, as was observed by Sarkar and Dey (2010), Mignot et al. (2009a), and Dey and Das (2012). However, details of the turbulent bursting process will be described later in the manuscript using quadrant analysis.

The fourth-order moment of velocity fluctuations, also termed "coefficient of kurtosis" of the velocity fluctuations, signifies the intermittency of turbulence in the flow (Dey and Nath 2010). The vertical distributions of nondimensional fourth-order moment in streamwise and vertical directions

are defined as $F_{u}\left[=\overline{u^{\prime} u^{\prime} u^{\prime} u^{\prime}} /\left(\overline{u^{\prime} u^{\prime}}\right)^{0.5 \times 4}\right]$, and $F_{w}\left[=\overline{w^{\prime} w^{\prime} w^{\prime} w^{\prime}} /\left(\overline{w^{\prime} w^{\prime}}\right)^{0.5 \times 4}\right]$. The kurtosis for a standard Gaussian distribution is 3 and the "excess kurtosis" is thus defined as $F_{u}-3$. According to Fig. 10, the vertical distributions of $F_{u}$ and $F_{w}$ are almost similar although below $z_{1}=0, F_{u}>F_{w}$. The value of $F_{u}$ and $F_{w} \approx 3$ above $z_{1}=0$ and its value increases slowly below this level up to the level $z=0$. Below $z=0$, the $F_{u}$ and $F_{w}$ depart sharply from the Gaussian value of 3, indicating high intermittencies in the near-bed region of flows in both the streamwise and vertical directions.

\section{DISTRIBUTIONS OF TURBULENT LENGTH SCALES}

Turbulent flow contains eddies of larger and smaller sizes; the properties of those can be studied by using different length scales. Out of these eddies, the smaller ones are associated with pure turbulence and their sizes can be calculated by using Taylor microscale and Kolmogorov microscale (Dey 2014). The Taylor microscale is used to measure eddies in the inertial subrange, whereas the Kolmogorov microscale is used to measure eddies in the dissipation range of the energy spectrum. Another length scale was introduced by Prandtl (1925) in order to describe the momentum transfer by turbulence Reynolds stresses within a fluid flow that is called as Prandtl's mixing length. 

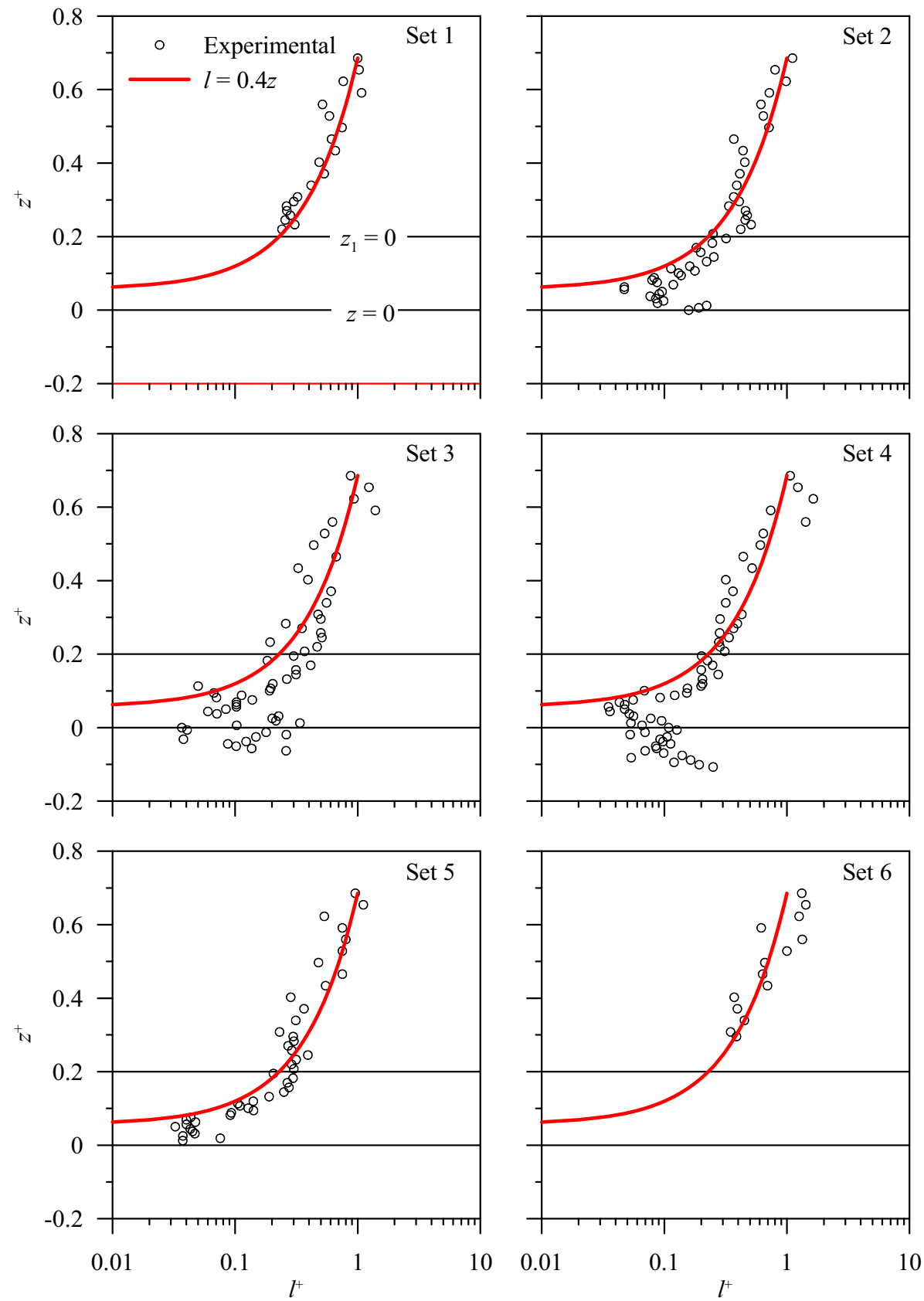

Fig. 11. Variations of nondimensional Prandtl's mixing length $l^{+}$with $z^{+}$. 
The Prandtl mixing length $l$ is calculated from the equation $l=\left[-\overline{u^{\prime} w^{\prime}} /\right.$ $\left.(d u / d z)^{2}\right]^{0.5}$. The nondimensional value of $l$ is $l^{+}=l / d_{50}$. The nondimensional Prandtl mixing length $l^{+}$as a function of $z^{+}$is plotted in Fig. 11. In general, the vertical distribution of $l^{+}$is almost similar for all the locations above $z^{+}=0$ and in conformity with the relationship $l=\kappa z$, where $\kappa=$ von-Karman constant $(=0.4)$. On the other hand, below $z^{+}=0$, the value of $l^{+}$increases and departs from the theoretical value. However, Dey and Nath (2010) reported that the estimations of $l^{+}$and $\kappa$ from the Vectrino measurements are always error prone and specific features of individual parameters are interpreted with carefulness.

According to Dey and Das (2012), the Taylor microscale can be defined as:

$$
\lambda=\left(\frac{15 v \overline{u^{\prime} u^{\prime}}}{\varepsilon}\right)^{0.5}
$$

and nondimensionalized as: $\lambda^{+}=\lambda / d_{50}$, where $\varepsilon=$ TKE dissipation rate obtained from Kolmogorov's second hypothesis.

The values of $\varepsilon$ can also be estimated by using $\left(15 v / u^{2}\right) \overline{\left(\partial u^{\prime} / \partial t\right)^{2}}$, as was done by Irwin (1973), and Krogstad and Antonia (1999). But, it was experienced that the later method for calculating $\varepsilon$ is not suitable for the data below crest level because of very inconsistent values. However, it is observed from Fig. 12 that the value of $\lambda^{+}$increases with an increase in the vertical distance within $z_{1}=0$ and reaches the peak value at $z_{1}=0$. Above this level, the value of $\lambda^{+}$becomes almost invariant with further increase in vertical distance. The trend of $\lambda^{+}$is almost similar to that of Dey and Das (2012), who found that $\lambda^{+}$increases with the vertical distance up to the crest level and becomes independent of vertical distance above the crest level of the gravel-bed. Below the crest level, the values of $\lambda^{+}$decrease with decrease in vertical distance.

On the contrary, Mignot et al. (2009a) found that the value of $\lambda^{+}$increases below the virtual bed-level and above the virtual bed level, the value becomes invariant with vertical distance. Dey and Das (2012) pointed out the cause behind this discrepancy is the method of estimating $\varepsilon$.

The Kolmogorov microscale is the smallest scale in turbulent flow. Mathematically, the DA quantity of this scale is defined as:

$$
\eta=\left(v^{3} / \varepsilon\right)^{0.25}
$$

and it is nondimensionalized as: $\left\langle\eta^{+}\right\rangle=\eta / d_{50}$. It is clear from Fig. 12 that the trend of Kolmogorov microscale is similar to that of Taylor microscale as 
with differences in values. This is also in conformation with Dey and Das (2012) and in contradiction with Mignot et al. (2009a).
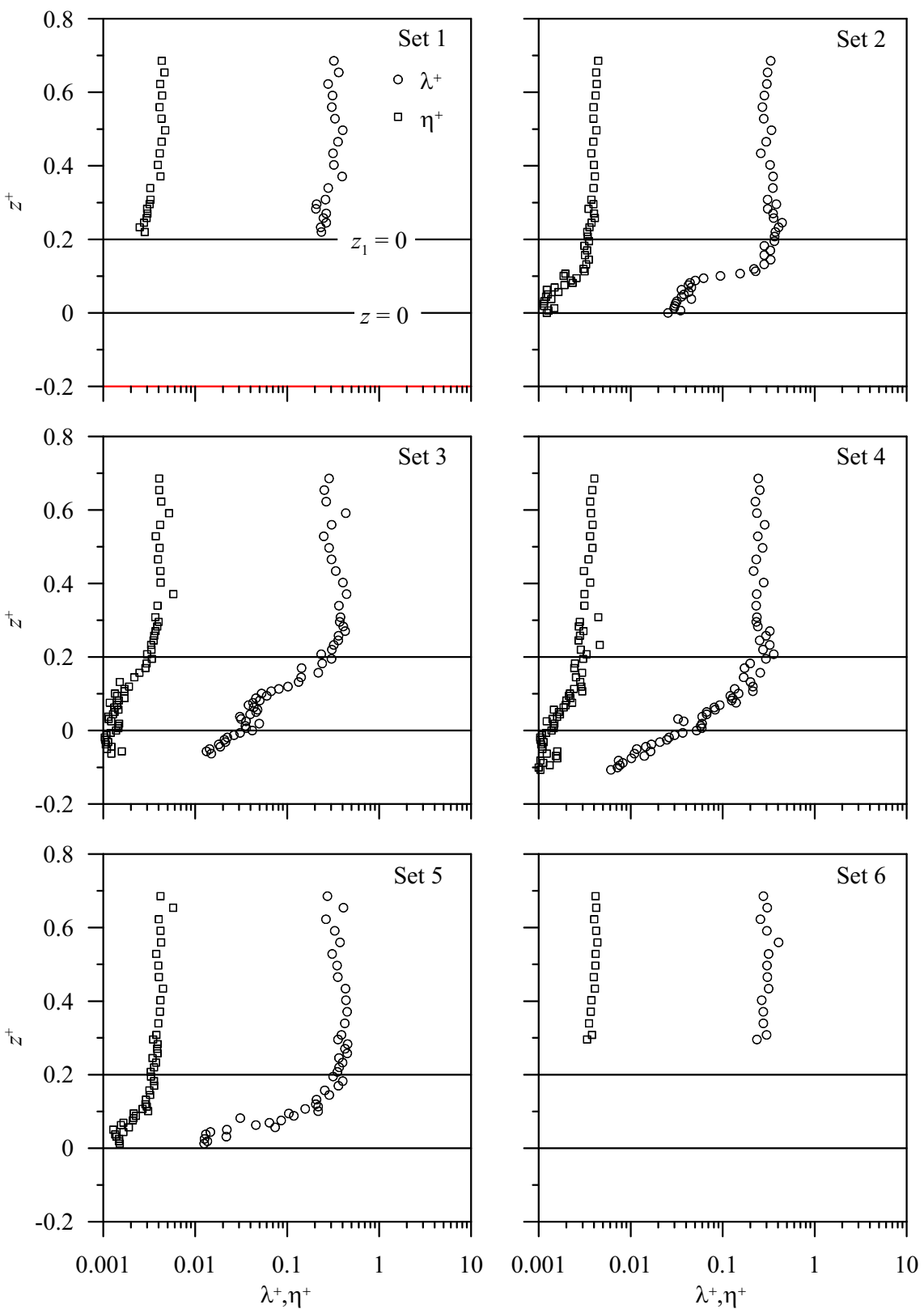

Fig. 12. Variations of nondimensional Taylor and Kolmogorov microscales, $\lambda^{+}$and $\eta^{+}$with $z^{+}$. 


\section{TURBULENT BURSTING}

The quadrant analysis introduced by Lu and Willmarth (1973) was used to observe the characteristics of the bursting events. According to the quadrant analysis, the fluctuations $u^{\prime}$ and $w^{\prime}$ are divided into four quadrants to evaluate the contributions of the bursting events. The quadrants are defined as: (i) first quadrant: outward interactions with $u^{\prime}>0$ and $w^{\prime}>0$, (ii) second quadrant: ejections $u^{\prime}<0$ and $w^{\prime}>0$, (iii) third quadrant: inward interactions with $u^{\prime}<0$ and $w^{\prime}<0$, and (iv) fourth quadrant: sweeps with $u^{\prime}>0$ and $w^{\prime}<0$.

A hole-size parameter $H$, determined by the curve $\left|u^{\prime} w^{\prime}\right|=H\left(u_{r m s}^{\prime} \times\right.$ $\left.w_{r m s}^{\prime}\right)$, is used to differentiate the fractional contributions to $-\overline{u^{\prime} w^{\prime}}$ at four different quadrants. In order to consider all the data pairs $\left(u^{\prime}, w^{\prime}\right)$, the holesize $H=0$ is used.

The contributions to the total RSS production from the quadrant $i$ outside the hole region of size $H$ are estimated by

$$
\overline{u^{\prime} w_{i, H}^{\prime}}=\underset{T \rightarrow \infty}{L t} \frac{1}{T} \int_{0}^{T} u^{\prime}(t) w^{\prime}(t) \phi_{i, H}(z, t) d t
$$

where $T$ is the time of sampling and $\phi_{i, H}(t)$ is the detection function given by $\phi_{i, H}(t)=1$, if $\left(u^{\prime}, w^{\prime}\right)$ is in quadrant $i$ and if $\left|u^{\prime} w^{\prime}\right| \geq H\left(u_{r m s}^{\prime} \times w_{r m s}^{\prime}\right)$; otherwise, $\phi_{i, H}(t)=0$.

The fractional contributions of conditional RSS can be calculated by

$$
R S_{i, H}=\overline{u^{\prime} w^{\prime}}{ }_{i, H} / \overline{u^{\prime} w^{\prime}}
$$

The algebraic summation of contributions from all the bursting events for $H=0$ is therefore unity, that is, $\left.\sum_{i=0}^{i=4} R S_{i, H}\right|_{H=0}=1$.

To study the frequencies of the bursting events, the appearances of an event in a recorded sample were added up for a given hole-size $H$ by counting the times of switching over of the series of $\left(u^{\prime}, w^{\prime}\right)$. Then, a mean timeduration and the mean frequencies corresponding to that event were determined. The nondimensional mean frequencies of the bursting events are $\hat{f}_{1,0}\left(=i_{1,0}{ }^{-1} h / u_{*}\right), \hat{f}_{2,0}\left(=i_{2,0}{ }^{-1} h / u_{*}\right), \hat{f}_{3,0}\left(=i_{3,0}{ }^{-1} h / u_{*}\right)$, and $\hat{f}_{4,0}\left(=i_{4,0}{ }^{-1} h / u_{*}\right)$, respectively, where $i_{1,0}, i_{2,0}, i_{3,0}$, and $i_{4,0}$ are the mean intervals of the occurrence of the same event.

Figure 13 shows the vertical variations of conditional Reynolds shear stresses $R S_{i, H}$ with $z^{+}$for $H=0$. As indicated from the distributions of thirdorder moments of velocity fluctuations, the general trends of the $R S_{i, H}$ are same above $z^{+}=0.1$, with difference in values. Irrespective of the locations, 

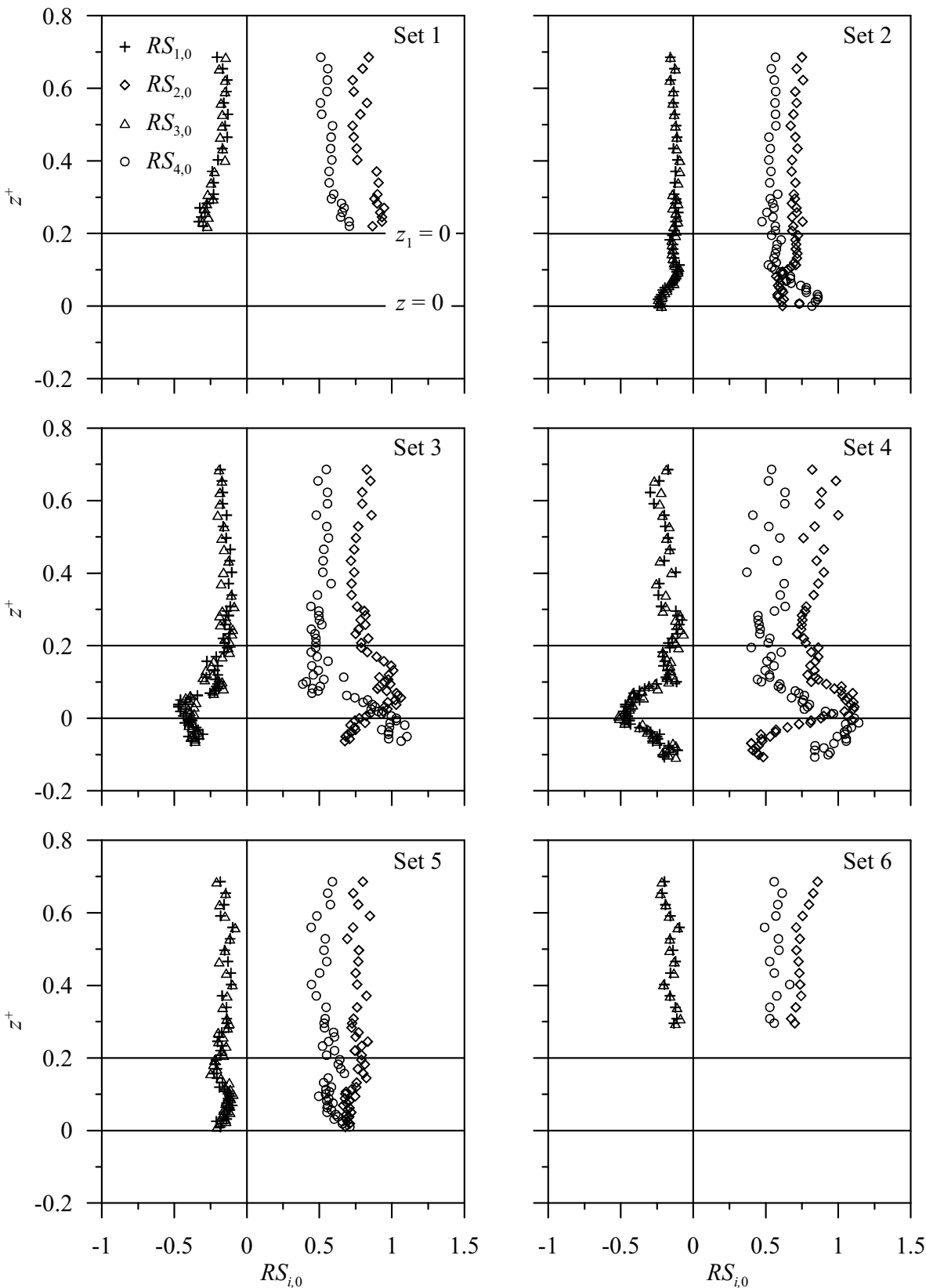

Fig. 13. Variations of conditional Reynolds shear stresses $R S_{i, H}$ with $z^{+}$for $H=0$. 

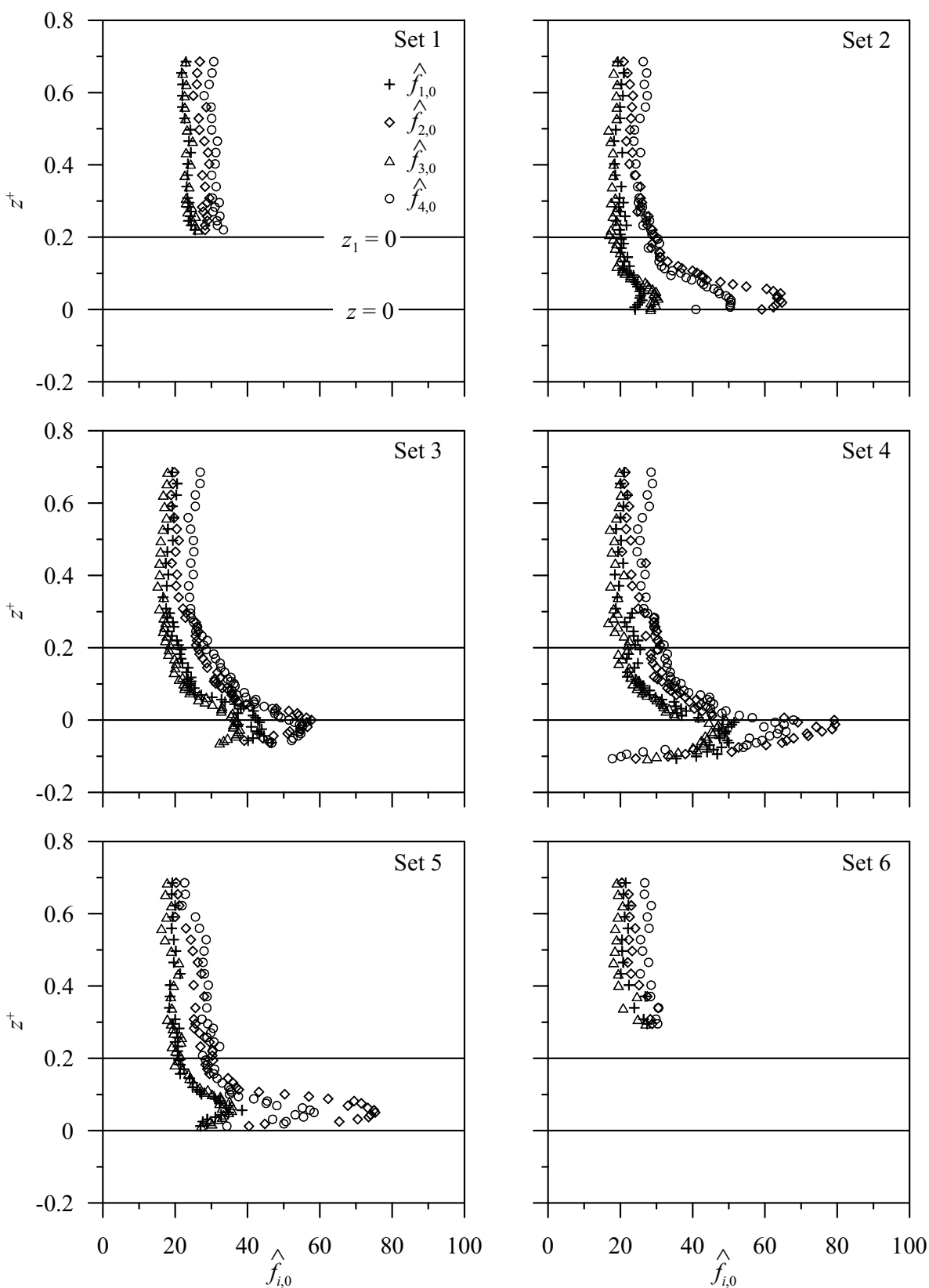

Fig. 14. Variations of nondimensional mean frequencies of the bursting events $\hat{f}_{i, H}$ with $z^{+}$for $H=0$. 
for the vertical distances above $z^{+}=0.1$, ejections is the governing mechanism. On the other hand, the dominance of the bursting events change below $z^{+}=0.1$. Below $z^{+}=0$, sweeps is the predominating event as found for the data Sets 3 and 4 and above $z^{+}=0$, the changeover of the dominance of the bursting events takes place. However, for the data Set 2 (immediate downstream of the protruding gravel), the sweeps event predominates up to $z^{+} \leq$ 0.1 . On the other hand, the contributions of inward and outward interactions are relatively small irrespective of the vertical distances and locations of the measurements. It is therefore concluded that the bursting events are affected by the presence of protrusion, as observed by Dey et al. (2011), and the changeover of the bursting events takes place due to the local roughness in the bed, as observed by Sarkar and Dey (2010), Mignot et al. (2009a), and Dey and Das (2012).

Figure 14 shows the vertical distributions of nondimensional mean frequencies of the bursting events. It is evident from Fig. 14 that the general trends of the frequencies of all the events are similar above $z^{+}=0.2$, irrespective of the location of the measurements. Frequencies of the sweeps and ejections are greater than those of the outward and inward interactions. Immediate downstream of the protruding gravels, the frequencies of all the events increase, which is in confirmation with Dey et al. (2011). On the other hand, frequency of all the events increases sharply to a peak value at $z^{+}=0$ for the data Sets 3 and 4 and then decreases with decrease in $z^{+}-$ values. This is due to the effect of local roughness. It is pertinent to mention here that Sarkar and Dey (2010) also found similar variations of mean frequencies of sweeps and ejections for the flow over a gravel bed. However, in the present case the trends of mean frequencies of inward and outward interactions are also same as sweeps and ejections, but their values are less than that of sweeps and ejections.

\section{CONCLUSIONS}

Turbulent characteristics over a gravel-bed protruded with an array of larger gravels have been studied experimentally using the time-averaging methodology. The vertical distributions of time-averaged streamwise velocity, Reynolds shear and normal stresses, turbulent kinetic energy, higher-order moments (skewness and kurtosis) of velocity fluctuations, length scales (Prandtl's mixing length, and Taylor and Kolmogorov microscales), and turbulent bursting were measured at different locations. Six measuring locations were chosen in such a way that two locations were onto the crest level of the larger protruding gravel, two were onto the crest level of the gravelbed, one was at the junction between two gravels of the bed, and one was at the aperture between two gravels of the bed. It was observed that the turbu- 
lent characteristics do not vary significantly above the crest level of the protruding array at different locations. On the other hand, the streamwise velocity decreases with a decrease in depth below the array. Below the array, the Reynolds shear stress deviates from the gravity-law of Reynolds shear stress. Turbulence intensities in streamwise, lateral and vertical directions reduce significantly below the gravel-bed. Fourth-order moments of velocity fluctuations increase below the crest level of the gravel-bed. The third-order moments of velocity fluctuations increase below the crest level of the gravelbed and give a clear indication of sweeps as the predominating events. Kolmogorov and Taylor microscales reduce below the crest level; whereas the value of Prandtl's mixing length below the crest level of the gravel-bed. The quadrant analysis results show that sweeps are the governing mechanism below the crest level of the gravel bed and as the vertical distance increases ejections become predominating. At the immediate downstream of the gravel array, sweeps predominate up to a certain vertical distance due to the effect of protrusion. The contributions of outward and inward interactions remain smaller than those of sweeps and ejections irrespective of the vertical distance and local roughness in the bed. The mean frequencies of all the bursting events increase in the presence of protrusion. Their values increase sharply at the crest level of the gravel bed and then decrease with decrease in vertical distance. The mean frequencies of ejections and sweeps are greater than those of inward and outward interactions throughout the depth.

Acknowledgements. The author would like to thank the reviewers for their valuable comments that greatly improved the manuscript.

\section{References}

Aberle, J., K. Koll, and A. Dittrich (2008), Form induced stresses over rough gravelbeds, Acta Geophys. 56, 3, 584-600, DOI: 10.2478/s11600-008-0018-x.

Acarlar, M.S., and C.R. Smith (1987), A study of hairpin vortices in a laminar boundary layer. Part 1 . Hairpin vortices generated by hemisphere protuberance, J. Fluid Mech. 175, February, DOI: 10.1017/S0022112087000272.

Best, J.L. (1996), The fluid dynamics of small-scale alluvial bedforms. In: P. Carling and M.R. Dawson (eds.), Advances in Fluvial Dynamics and Stratigraphy, John Wiley, Hoboken, 67-125.

Best, J.L., and A.C. Brayshaw (1985), Flow separation - A physical process for the concentration of heavy minerals within alluvial channels, J. Geol. Soc. 142, 5, 747-755, DOI: 10.1144/gsjgs.142.5.0747. 
Brayshaw, A.C. (1984), Characteristics and origin of cluster bedforms in coarsegrained alluvial channels. In: E.H. Koster and R.J. Steel (eds.), Sedimentology of Gravels and Conglomerates, Canadian Society of Petroleum Geologist, Calgary, Canada, 77-85.

Buffin-Bélanger, T., and A.G. Roy (1998), Effects of a pebble cluster on the turbulent structure of a depth-limited flow in a gravel-bed river, Geomorphology 25, 3-4, 249-267, DOI: 10.1016/S0169-555X(98)00062-2.

Buffin-Be'langer, T., S. Rice, I. Reid, and J. Lancaster (2006), Spatial heterogeneity of near-bed hydraulics above a patch of river gravel, Water Resour. Res. 42, 4, W04413, DOI: 10.1029/2005WR004070.

Dey, S. (2014). Fluvial Hydrodynamics: Hydrodynamic and Sediment Transport Phenomena, Geoplanet: Earth and Planetary Sciences, Springer Verlag, Berlin, DOI: 10.1007/978-3-642-19062-9.

Dey, S., and R. Das (2012), Gravel-bed hydrodynamics: Double-averaging approach, J. Hydraul. Eng. 138, 8, 707-725, DOI: 10.1061/(ASCE)HY.19437900.0000554 .

Dey, S., and T.K. Nath (2010), Turbulence characteristics in flows subjected to boundary injection and suction, J. Eng. Mech. ASCE 136, 7, 877-888, DOI: 10.1061/(ASCE)EM.1943-7889.0000124.

Dey, S., S. Sarkar, S.K. Bose, S. Tait, and O. Castro-Orgaz (2011), Wall-wake flows downstream of a sphere placed on a plane rough-wall, J. Hydraul. Eng. 137, 10, 1173-1189, DOI: 10.1061/(ASCE)HY.1943-7900.0000441.

Duncan, W.J. (1970), Mechanics of Fluids, Elsevier, New York.

Gad-el-Hak, M., and P. Bandyopadhyay (1994), Reynolds number effects in wallbound turbulent flow, Appl. Mech. Rev. 47, 8, 307-365, DOI: 10.1115/ 1.3111083 .

Goring, D.G., and V.I. Nikora (2002), Despiking acoustic Doppler velocimeter data, J. Hydraul. Eng. 128, 1, 117-126, DOI: 10.1061/(ASCE)0733-9429(2002) 128:1(117).

Irwin, H.P.A.H. (1973), Measurements in a self-preserving plane wall jet in a positive pressure gradient, J. Fluid Mech. 61, 1, 33-63, DOI: 10.1017/ S0022112073000558.

Kirkbride, A.D. (1993), Observations of the influence of bed roughness on turbulence structure in depth limited flows over gravel beds. In: N.J. Clifford, J.R. French, and J. Hardistry (eds.), Turbulence, Perspectives on Flow and Sediment Transport, Wiley, Chichester, 185-196.

Krogstad, P.A., and R.A. Antonia (1999), Surface roughness effects in turbulent boundary layers, Exp. Fluids 27, 5, 50-460, DOI: 1007/s003480050370.

Lacey, R.W.J., and A.G. Roy (2007), A comparative study of the turbulent flow field with and without a pebble cluster in a gravel bed river, Water Resour. Res. 43, 5, W05502, DOI: 10.1029/2006WR005027. 
Lacey, R.W.J., P. Legendre, and A.G. Roy (2007), Spatial-scale partitioning of in situ turbulent flow data over a pebble cluster in a gravel-bed river, Water Resour. Res. 43, 3, W03416, DOI: 10.1029/2006WR005044.

Lu, S.S., and W.W. Willmarth (1973), Measurements of the structure of the Reynolds stress in a turbulent boundary layer, J. Fluid Mech. 60, 3, 481-511, DOI: $10.1017 / \mathrm{S} 0022112073000315$.

Mignot, E., E. Barthelemy, and D. Hurther (2009a), Double-averaging analysis and local flow characterization of near-bed turbulence in gravel-bed channel flows, J. Fluid Mech. 618, 279-303, DOI: 10.1017/S002211200800464.

Mignot, E., D. Hurther, and E. Barthelemy (2009b), On the structure of shear stress and turbulent kinetic energy flux across the roughness layer of a gravel-bed channel flow, J. Fluid Mech. 638, 423-452, DOI: 10.1017/ S0022112009990772.

Nikora, V., D. Goring, I. McEwan, and G. Griffiths (2001), Spatially averaged openchannel flow over rough bed, J. Hydraul. Eng. 127, 2, 123-133, DOI: 10.1061/(ASCE)0733-9429(2001)127:2(123).

Nikora, V., K. Koll, I. McEwan, S. McLean, and A. Dittrich (2004), Velocity distribution in the roughness layer of rough-bed flows, J. Hydraul. Eng. 130, 10, 1036-1042, DOI: 10.1061/(ASCE)0733-9429(2004)130:10(1036).

Nikora, V., I. McEwan, S. McLean, S. Coleman, D. Pokrajac, and R. Walters (2007a), Double-averaging concept for rough-bed open-channel and overland flows: Theoretical background, J. Hydraul. Eng. 133, 8, 873-883, DOI: 10.1061/(ASCE)0733-9429(2007)133:8(873).

Nikora, V., S. McLean, S. Coleman, D. Pokrajac, I. McEwan, L. Campbell, J. Aberle, D. Clunie, and K. Koll (2007b), Double-averaging concept for rough-bed open-channel and overland flows: Applications, J. Hydraul. Eng. 133, 8, 884-895, DOI: 10.1061/(ASCE)0733-9429(2007)133:8(884).

Papanicolaou, A.N., C.M. Kramer, A.G. Tsakiris, T. Stoesser, S. Bomminayuni, and Z. Chen (2012), Effects of a fully submerged boulder within a boulder array on the mean and turbulent flow fields: Implications to bedload transport, Acta Geophys. 60, 6, 1502-1546, DOI: 10.2478/s11600-012-0044-6.

Prandtl, L. (1925), Bericht über untersuchungen zur ausgebildeten turbulenz, Z. Angew. Math. Mech. 5, 2, 136-139, DOI: 10.1007/978-3-662-118368_57 (in German).

Raupach, M.R. (1981), Conditional statistics of Reynolds stress in rough-wall and smooth-wall turbulent boundary layers, J. Fluid Mech. 108, July, 363-382, DOI: $10.1017 / \mathrm{S} 0022112081002164$.

Sarkar, S., and S. Dey (2010), Double-averaging turbulence characteristics in flows over a gravel-bed, J. Hydraul. Res. 48, 6, 801-809, DOI: 10.1080/ 00221686.2010 .526764 .

Tamagni, S., V. Weitbrecht, and R.M. Boes (2014), Experimental study on the flow characteristics of unstructured block ramps, J. Hydraul. Res. 52, 5, 600613, DOI: 10.1080/00221686.2014.950610. 
Van Zyll De Jong, M.C., I.G. Cowx, and D.A. Scruton (1997), An evaluation of instream habitat restoration techniques on salmonid populations in a Newfoundland stream, Regul. Rivers Res. Manage. 13, 6, 603-614, DOI: 10.1002/(SICI)1099-1646(199711/12)13:6<603::AID-RRR487>3.0.CO;2-Y.

Received 3 December 2015 Received in revised form 21 January 2016 Accepted 8 February 2016 